\title{
TECNOLOGIA DE INFORMAÇÃO E MUDANÇA: UMA ABORDAGEM CRÍTICA
}

\author{
Claudio Pitassi \\ Mestre em Administração de Empresas e Doutorando em Administração de Empresas na PUC-RJ. \\ E-mail: cpitassi@cvrd.com.br \\ Sergio Proença Leitão \\ Mestre em Administração de Empresas, Doutor em Educação e Professor Associado do \\ Departamento de Administração de Empresas da PUC-RJ. \\ E-mail: proenca@iag.puc-rio.br
}

\begin{abstract}
RESUMO
Este artigo caracteriza-se pela análise crítica da perspectiva puramente instrumental e tecnicista dos seguidores da Tecnologia de Informação (TI). Nessa crítica, diferenciam-se as mudanças adaptativas das mudanças paradigmáticas e restringe-se a mudança habilitada pela TI aos esforços para melhorar a performance das organizações ainda dentro do paradigma dominante. Assim, evidencia-se como as distorções, causadas pela razão instrumental na percepção dos stakeholders a respeito dos fenômenos de informação, linguagem, comunicação e cognição, implicam sérios problemas para a gestão estratégica de sistemas de informação. Em que pesem as sérias conseqüências dessas distorções, defende-se que o fetiche da TI traz prejuízos ainda maiores, ao induzir à ilusão de que ela, sozinha, pode

mudar o mundo. Partindo-se do princípio de que, para confrontar a visão instrumental, são necessárias novas epistemologias, apresentam-se elementos da visão sistêmica, da teoria crítica e do pós-modernismo. Por fim, propõese uma mudança paradigmática e ideológica, fundada em uma razão substantiva que propicie um desenvolvimento sustentado e a prática da justiça social, buscando um debate ético-valorativo da mudança.
\end{abstract}

\section{ABSTRACT}

This article critically analyzes the purely "tecnicist" and instrumental perspective that prevails in the information technology (IT) literature. The adaptive changes are differentiated from the paradigmatic changes, and the changes enabled by the IT are restricted to the efforts to improve the organization performance still within the dominant paradigm. Within the adaptive changes facilitated by IT, it is discussed how the distortions caused by the instrumental reasoning in the stakeholders' perception of the nature of information, language, communication and cognition seriously hurt the strategic management of information systems. Without neglecting the consequences of these distortions, it is defended that the IT myth brings consequences even worse, once this conception assumes that IT, by itself, can change the world. Presupposing that, to confront the myth, new epistemologies are necessary, aspects of

the systemic view, critical theory and post-modernism are presented. To overcome the limits of the instrumental reasoning, the article suggests a paradigmatic and ideological change perspective, supported by a substantive reason that direct people's actions towards the search of ecology equilibrium and the practice of social justice, situating the debate of the change process on an ethical perspective.

PALAVRAS-CHAVE

Tecnologia de informação, razão instrumental, informação, comunicação, linguagem.

KEY WORDS

Information technology, instrumental reason, information, communication, language. 


\section{INTRODUÇÃO}

O mito criado em torno dos benefícios que a tecnologia em geral e a Tecnologia de Informação (TI) em particular inexoravelmente trazem para a humanidade deixa nos mais incautos a sensação de estarmos no limiar de uma nova sociedade, já denominada "economia da informação", inerente ao que se está chamando de "sociedade do conhecimento". Nessa perspectiva, assume-se o pressuposto de que a tecnologia resolverá os problemas da humanidade. No entanto, a tecnologia não é capaz de determinar nada por si só, pois é utilizada dentro de um contexto político-ideológico mais amplo.

Por conseguinte, um olhar crítico sugere algumas questões mais substanciais: pode-se afirmar que, a partir de uma perspectiva humanista, há, a priori, algo de realmente novo na sociedade do conhecimento? Partindo-se do pressuposto de que o conhecimento estará sempre mediado por algum tipo de ideologia, cabe perguntar: Quais são os paradigmas subjacentes ao conhecimento proporcionado pela abundância de informação? Ou seja, em que ontologia - que trata da natureza, da essência e da dinâmica do objeto de estudo - e em que epistemologia - que estuda os princípios e pressupostos aplicados ao conhecimento desse objeto - essa nova sociedade pretende fundamentar o seu saber?

A literatura tradicional de management, dominada por uma hipertrofia da razão instrumental e pelo paradigma funcionalista, praticamente ignora essas questões substanciais, muito embora proliferem as preocupações com as mudanças de hábitos (Negroponte, 1995), de processos e de modelos de negócios (Venkatraman, 1994) que a TI, particularmente a Internet, trará em seu bojo. Nessa literatura, a tecnologia assume um valor moralmente construtivo (Leitão e Rossi, 2000), e a discussão das mudanças fica restrita aos aspectos práticos, às etapas e aos riscos da implantação das mudanças subjacentes ao desenvolvimento inevitável e transformador da tecnologia. A visão instrumental aplicada ao processo de implantação dos sistemas de informação resulta na deformação do entendimento da natureza da informação, da linguagem e da comunicação, com sérias conseqüências para as organizações produtivas.

Percebe-se, nos autores ligados à TI, um fascínio que denuncia uma relação de causalidade entre "novas e melhores formas de pensar e fazer" e a TI, na qual esta última constitui o fator desencadeador. É como se o desenvolvimento da tecnologia fosse capaz, por si só, de acarretar uma mudança ideológica e paradigmática no modelo de gestão das organizações e na qualidade do relacionamento das organizações com o ambiente - particularmente na percepção dos acionistas e dos gestores sobre a responsabilidade das organizações pela produção de um bem-estar social e pelo equilíbrio ecológico do planeta. De um momento a outro, dá-se um salto de uma sociedade cujos valores estão superados para outra muito me- lhor, que não se sabe muito bem o que seja, mas cujo portal mágico é a TI. Prevalece, nesse caso, um aprendizado supersticioso, no qual a conexão entre as ações e os resultados é totalmente enganosa (Levitt e March, 1996).

Este artigo analisa, criticamente, a perspectiva "tecnicista" da literatura de TI, particularmente as deformações causadas pelo paradigma funcionalista e pela hipertrofia da razão instrumental no conceito e no uso da informação nas organizações tradicionais, e busca definir a natureza e os limites da mudança acarretada pela introdução crescente da TI no ambiente organizacional. Nessa análise, distinguem-se as mudanças adaptativas das mudanças transformadoras, fundamentadas na emergência de uma razão substantiva que possibilite um desenvolvimento sustentado e a prática da justiça social. No esforço de interpretação crítica, será utilizado, principalmente, o referencial teórico da visão sistêmica. Dada a natureza dos assuntos discutidos, a linguagem utilizada não é de fácil leitura para os iniciantes. Para reduzir essa dificuldade, procurar-se-á definir os conceitos, sempre que apropriado.

\section{MUDANÇAS TRANSFORMADORAS E MUDANÇAS ADAPTATIVAS}

Atualmente, fala-se muito em mudanças de paradigma, sobretudo quando se avalia o impacto da Internet nas organizações. Mas o que se entende por mudanças de paradigma? De acordo com Burrel (1999), os paradigmas definem uma forma de ver o mundo e de como ele deve ser estudado. Esse ponto de vista passa a ser compartilhado por um grupo de cientistas que vive em uma comunidade marcada por uma linguagem comum, busca fundar um edifício conceitual igualmente comum e possui uma postura política defensiva. Assim, mudar um paradigma envolve mudar os pressupostos do conhecimento que o determina e também as crenças, os valores e a ideologia a ele associados (Leitão e Rossi, 2000).

Segundo a conhecida tipologia de Burrel e Morgan (1982), podem-se ligar as mudanças adaptativas aos paradigmas funcionalista e interpretativo, e as mudanças transformadoras, aos paradigmas do humanismo radical e do estruturalismo radical. O funcionalismo está comprometido com a manutenção da ordem e da estabilidade da sociedade ao procurar regularidades com o objetivo de predição e controle dos fenômenos sociais, de acordo com a ciência positivista. Sua concepção de mudança, portanto, é de natureza reguladora ou adaptativa, atendendo à mobilidade natural do ambiente de negócios, sem questionar a cosmovisão e os fundamentos da ordem estabelecida ou as teorias dominantes a ela associadas, ou seja, uma concepção de mudança que não vem conduzindo aos resultados esperados (Chanlat, 2000; Birkner e Birkner, 1999; Stevenson e Greenberg, 1998; Van de Ven e Poole, 1995). 
Um paradigma é, por outro lado, uma manifestação da ideologia dominante. Assim, assumimos, neste estudo, como Leitão e Rossi (2000) e Villardi e Leitão (2000), que uma mudança transformadora requer mudança do paradigma dominante - o funcionalismo - e da ideologia a ele associada - o produtivismo.

No nível da organização produtiva, o estrutural-funcionalismo, como preferem outros autores, tem sido a visão dominante. De acordo com essa visão, o papel do gerente é reativo: coleta a informação correta sobre o meio ambiente e utiliza critérios técnicos para examinar as conseqüências das respostas às estratégias alternativas, nesse caso, as mudanças assumem a forma de adaptações ao meio ambiente (Astley e Van de Ven, 1983). É uma visão de mundo em que "a mudança se dá nos limites da técnica instrumentalizadora e dos valores e crenças do produtivismo, que são percebidos como possibilidade única para as organizações sociais" (Leitão e Rossi, 2000). Dentro dessa lógica instrumental, a TI, ao disponibilizar mais informação sobre o ambiente, tem o poder de melhorar a qualidade da decisão gerencial aplicada no processo de mudança organizacional e, conseqüentemente, de acelerála. Com base no pressuposto de que toda mudança transformadora requer mudança paradigmática, cabe uma questão: Quais as limitações da mudança comandada pela TI?

IMPACTO DA TI: UMA

MUDANÇA DE PARADIGMA?

Alguns títulos de livros e artigos que discutem o impacto da TI sugerem que uma transformação profunda está em curso nas organizações e na sociedade: Paradigm shif: the new promisse of information technology (Tapscott e Caston, 1993); A empresa na velocidade do pensamento (Gates, 1999); A vida digital (Negroponte, 1995); Blur: the speed of change in the connected economy (Davis e Meyer, 1998); Blow to bits: how the new economics of information transform strategy (Evans e Wurster, 2000); Shaping the future: business design through information technology (Keen, 1991); IT-enabled business transformation: from automation to business scope redefinition (Venkatraman,1994).

Negroponte (1995, p. 12) propõe que a transformação de átomos em bits trará profundas alterações na cultura e no padrão de relacionamento entre as pessoas: "À medida que formos nos interconectando, muitos dos valores nacionais cederão lugar àqueles de comunidades eletrônicas maiores ou menores. Nós nos socializaremos em bairros digitais, nos quais o espaço físico será irrelevante e o tempo desempenhará um papel diferente."

À proporção que a informação passa a desempenhar um papel cada vez mais relevante nos relacionamentos comerciais, há uma mudança profunda nas regras da economia, já que as regras que governam o mundo físico são bastante diferentes das que comandam o mundo da informação, pois estas não se encontram limitadas pelas barreiras de tempo e espaço do mundo físico (Evans e Wurster, 2000).

Com o aumento da velocidade dos negócios (Gates, 1999), com o desenvolvimento das tecnologias de integração com parceiros (Venkatraman, 1994) e com a transformação das estruturas organizacionais (Tapscott e Caston, 1993), a própria natureza da organização estaria mudando. Nessa perspectiva, o desenvolvimento contínuo da capacidade tecnológica de compartilhar e usar a informação teria o poder de redefinir negócios e indústrias e de mudar a natureza da vantagem competitiva (Evans e Wurster, 2000). Na economia da informação e da WEB, prevaleceriam as organizações virtuais, holográficas ou em co-produção (Ramirez, 1999).

\section{A VISÃO INSTRUMENTAL APLICADA AO PROCESSO DE IMPLANTAÇÃO} DOS SISTEMAS DE INFORMAÇÃO RESULTA NA DEFORMAÇÃO DO ENTENDIMENTO DA NATUREZA

\section{DA INFORMAÇÃO, DA LINGUAGEM E DA COMUNICAÇÃO, COM} SÉRIAS CONSEQÜÊNCIAS PARA

\section{AS ORGANIZAÇÕES PRODUTIVAS.}

Um tema recorrente na literatura de TI é o conceito de alinhamento estratégico (Lockamy e Smith, 1997), surgido nas empresas ocidentais quando muitas corporações perceberam que estavam desenvolvendo sistemas de informação os quais não sustentavam suas estratégias de negócio (Bensaou e Earl, 1998). Nessa perspectiva, o alinhamento é visto como um mecanismo de defesa contra os comprovados fracassos do passado e os riscos cada vez maiores do futuro e também como busca de um novo equilíbrio entre ambiente interno e externo. Assim, a principal preocupação de uma organização envolvida com a implementação de TI passa a ser a integração do processo de planejamento estratégico da TI ao processo de administração estratégica corporativa, em um contexto de mudança constante (Kovacevic e Majluf, 1993).

Mas de que mudanças estão falando esses pesquisadores e consultores? Nota-se claramente, na perspectiva do alinhamento estratégico da TI, o predomínio da visão reducionista e instrumental, que separa o ambiente interno e externo nas estratégias organizacionais (Leitão e Rossi, 2000), e na qual a questão da mudança é interpre- 
tada como um problema técnico e isolado, imune aos aspectos ideológicos e incapaz de incorporar uma visão sistêmica dos fenômenos organizacionais e da sociedade. Apoiando-se nos argumentos apresentados por Villardi e Leitão (2000, p. 2), pode-se afirmar que estamos diante de "um pensar tecnicista, acrítico e instrumentalmente despreocupado com a natureza do processo de mudança e em busca de resultados imediatos para acompanhar as transformações ambientais".

Qual o verdadeiro significado atribuído à mudança paradigmática e à mudança de mentalidade empresarial, sugeridas nos títulos das obras apresentadas acima? Uma perspectiva crítica evidencia que essas abordagens restringem-se a uma preocupação básica: como a TI pode ajudar a administrar melhor as organizações atuais, adaptando-as à realidade da economia da informação. Com esse objetivo, as novas regras das estratégias de negócio, fundamentadas na velocidade, na digitalização, na conectividade, no acesso universal à informação, no fim das hierarquias e no marketing reverso, servirão como instrumentos para aumentar a competitividade das organizações, jamais para mudar os paradigmas da sociedade em que se inserem. São, portanto, mudanças adaptativas, que visam à manutenção do status quo, ainda que venham embaladas por um discurso pseudo-revolucionário e repleto de clichês cibernéticos.

Neste artigo, não defendemos a idéia da inércia estrutural (Baum, 1999), em que a mudança adaptativa acarretada pela TI não é possível ou recomendada. Em alguns casos, o uso adequado da TI poderá resultar em melhoras significativas de performance e libertar o homem de tarefas repetitivas e enfadonhas. No entanto, a elevada taxa de fracasso e a descrença e o desinteresse da alta gestão nas implantações de TI que exijam mudanças comportamentais substanciais (Markus e Benjamin, 1997) sugerem que, mesmo no escopo limitado das mudanças adaptativas, a visão reducionista tem causado sérios problemas. Seria fortemente recomendável, então, que os gestores procurassem desenvolver uma compreensão melhor da natureza da informação e do fenômeno da cognição humana, caso se pretenda aumentar a efetividade da gestão estratégica de sistemas de informação.

\section{QUE É INFORMAÇÃO? QUAL A SUA NATUREZA?}

Freqüentemente, os defensores da TI advogam os benefícios da intensidade de informação como fonte de conhecimento e de transformação (De Almeida, 1995; Zuboff, 1994). Segundo Walsh (1995), a perspectiva da managerial cognition reduz os gerentes a trabalhadores da informação, cuja tarefa principal é absorver, processar e disseminar informação sobre as questões que causam impacto em sua organização. Nessa lógica cogniti- va linear, a TI teria a capacidade de criar informações e, assim, teria o potencial de aumentar a compreensão das operações nas organizações, o que levaria à mudança. No entanto, essas perspectivas "consideram a informação como uma estrutura unidimensional e adequada ao tratamento automatizado por parte de equipamentos eletrônicos, sem que haja preocupação ou crítica do resultado, se comparado às complexas estruturas cognitivas e afetivas envolvidas no processo decisório" (Gonçalves, 1996, p. 3).

Observa-se, portanto, que o termo informação tem sido utilizado em um sentido reducionista e equivocado pelos cientistas cartesianos, levando-os a confundir significado com sinais. Ao contrário, a informação é uma representação simbólica e formal de fatos ou idéias, potencialmente capaz de alterar o estado de conhecimento (Carvalho apud Gonçalves, 1996). Dado o caráter potencialmente transmissor de paradigmas da informação socialmente vivenciada, uma primeira preocupação é confrontar a idéia de que a informação é independente do contexto em que está inserida. "A visão convencional é a de que a informação, de alguma maneira, está 'situada lá fora', pronta para ser colhida pelo cérebro. No entanto, esse pedaço de informação é uma qualidade, um nome ou uma breve afirmação que nós abstraímos de toda uma rede de relações, de um contexto, no qual ela está encaixada e que lhe dá significado. Sempre que tal 'fato' estiver encaixado num contexto estável, que encontramos com grande regularidade, podemos abstraí-lo desse contexto, associá-lo com o significado inerente no contexto e chamá-lo de 'informação'. Estamos tão acostumados com essas abstrações que tendemos a acreditar que o significado reside no pedaço de informação, e não no contexto do qual ele foi abstraído" (Capra, 1996, p. 214)

O sistema nervoso humano não processa sinais já prontos no mundo exterior, mas interage com o meio ambiente, o que permite afirmar que todo conhecimento é contextual e grande parte dele é tácito e vivencial (Capra, 1996). Para a Biologia do Conhecimento, de Maturana e Varela (1995), o sistema nervoso não "capta informações" do meio e, sim, produz um mundo ao especificar que configurações do meio são perturbações e quais mudanças elas desencadeiam no organismo humano. Portanto, o que se tem hoje nas organizações sob o domínio da TI é uma objetivação total do significado, e não uma teoria da informação.

\section{TODA INFORMAÇÃO É OBJETIVA?}

As descobertas das neurociências sugerem que a inteligência, a memória e as decisões humanas não são completamente racionais, mas manifestam-se intermediadas pela vivência pessoal e pela emoção (Capra, 1996; Goleman, 1996). Por conseguinte, há que se fazer uma distinção entre a informação objetiva e a subjetiva (Jahn 
e Dunne, 1997). A primeira resulta dos mecanismos de processamento da informação utilizados para transmitir o conhecimento impessoal e pode ser quantificada em bits. A segunda, que não pode ser quantificada e transmitida eletronicamente, encontra-se imiscuída nos significados, valores, perspectivas, história pessoal e herança intelectual de quem a usa.

Logo, a informação não é dotada de um significado próprio, independente do indivíduo (Gonçalves, 1996). Para que a informação seja compreendida, aplica-se um processo mental, individual e inimitável de interpretação, o que explica por que a mesma informação "objetiva" suscita freqüientemente interpretações tão distintas dos tomadores de decisão (Gonçalves, 1996). No processo de conhecimento, o sujeito (o pensamento) e o objeto (o que se quer conhecer) estão em perpétua interação dialética, caracterizada por uma relação entre dois elementos opostos e ao mesmo tempo partes de um todo em constante diálogo (Lefebvre, 1979). Esse processo dialético, em que um signo, ao ser interpretado, tornase um novo signo, transformando também o sujeito do conhecimento, demonstra a metamorfose contínua ocorrida com os usuários da informação no processo de conhecimento (Gonçalves, 1996), com grandes implicações na gestão da TI.

Em uma perspectiva que procura ir além do subjetivismo individual, sugere-se mesmo que o conhecimento se realiza por meio da intersubjetividade, ou seja, das relações entre sujeitos, o que abre caminho na pesquisa acadêmica para o estudo do impacto dos relacionamentos sociais no processo de apreensão da realidade (Quincey, 1998). A coerência e a harmonia nas relações e interações entre os integrantes de um sistema social humano devem-se à coerência e à harmonia de seu crescimento dentro dele, em uma contínua aprendizagem social, que seu próprio operar social (lingüístico) define (Maturana e Varela, 1995).

\section{PODEM OS BITES TRANSMITIR \\ TODAS AS DIMENSÕES DA LINGUAGEM?}

Na visão moderna, a linguagem é vista como um instrumento transmissor de informação objetiva, o que é a base do pensamento cartesiano. Na literatura de TI, por exemplo, assume-se ser possível desenvolver sistemas capazes de fornecer, aprioristicamente e sem o julgamento do receptor, informação objetiva e homogênea (Gonçalves, 1996). Entretanto, o que as pessoas vêem da realidade à sua volta depende do que elas estejam preparadas para ver, e tal percepção é, em grande parte, transmitida pelos pressupostos embutidos na linguagem, um traço cultural de cada comunidade (Senge apud Remenyi et al., 1999).

O universo da palavra, do discurso e da linguagem transformam-se em um ponto-chave para a compreensão do conhecimento humano (Chanlat, 1992). Por meio da linguagem, definimos os limites de nosso convívio social e criamos nosso mundo (Capra, 1996).

\section{AS NOVAS REGRAS DAS}

\section{ESTRATÉGIAS DE NEGÓCIO}

\section{SERVIRÃO COMO INSTRUMENTOS}

\section{PARA AUMENTAR A COMPETITIVIDADE DAS ORGANIZAÇÕES, JAMAIS}

\author{
PARA MUDAR OS PARADIGMAS
}

\section{DA SOCIEDADE EM QUE SE INSEREM.}

\begin{abstract}
"A identidade dos sistemas sociais humanos depende, portanto, da conservação da adaptação dos seres humanos não só como organismos, no sentido geral, mas também como componentes dos domínios lingüísticos que constituem (...) para o operar de um sistema social humano o central é o domínio lingüístico que seus componentes geram" (Maturana e Varela, 1995, p. 224).

Nessa perspectiva, a linguagem define a realidade, age como uma janela que descortina os pressupostos das pessoas em sua interação social e desempenha um papel vital na eficácia dos sistemas de informação em um ambiente em constante mudança (Remenyi et al., 1999). Como se observa, reduzir a comunicação humana a uma simples transmissão de informação objetiva, como é feito freqüentemente nas organizações por influência direta da visão dominante inspirada na engenharia, é suprimir toda a questão do sentido e das significações (Chanlat, 1992).
\end{abstract}

\section{O COMPUTADOR PODE PENSAR?}

Diferentemente da inteligência do computador, que processa sinais, a inteligência humana processa informações. No processo cognitivo humano, a capacidade de abstração é uma característica única. É ela que nos permite pensar e nos relacionar por meio de representações mentais, símbolos e informações (Capra, 1996). Ser humano é ser dotado de uma consciência reflexiva, que nos possibilita saber que sabemos. Torna-se evidente, a partir do que foi descrito, a incapacidade dos computadores de serem inteligentes, uma vez que eles não podem abstrair e recorrer às experiências vividas e a outras formas de conhecimento além daquelas proporcionadas pelas operações formais (Capra, 1996; Maturana e Varela, 1995). 
COMO A COMUNICAÇÃO SOCIAL PODE AJUDAR NA IMPLANTAÇÃO DE SISTEMAS DE INFORMAÇÃO?

O conhecimento é um processo coletivo e cultural, e o entendimento realiza-se na relação ou comunicação com o outro. As perspectivas tradicionais da TI (Benjamim e Levinson, 1993) tratam a comunicação de forma instrumental, a ser utilizada para prover informação, criar o entendimento e construir o comprometimento entre as pessoas em momentos pontuais, como nas mudanças organizacionais. Entretanto, todo comportamento humano - e, portanto, toda interação - é comunicação e supõe um conjunto de disposições verbais e não verbais que exprimem, traduzem e registram o que se quer comunicar ao outro (Chanlat, 1992).

As interações sociais humanas constituem e são compostas pela comunicação (Ford e Ford, 1995). Dentro dessa perspectiva, a comunicação não é algo que se acione pontualmente para executar a mudança. Ao contrário, a mudança é que ocorre dentro do processo contínuo de comunicação, a qual é a base da própria existência humana. Diante disso, deve-se buscar compreender a natureza da própria comunicação, particularmente os aspectos da linguagem, do discurso e do poder a ela associados, caso se queira tornar as mudanças mais eficazes.

O corolário do conjunto das indagações acima confirma que o paradigma cartesiano-newtoniano não permite às organizações, e especialmente aos especialistas de TI, entenderem que as informações não criam idéias, mas as idéias criam informações construindo padrões integrativos que derivam da experiência (Roszak apud Capra, 1996). Ao contrário da visão predominantemente tecnicista dos pesquisadores de TI: "A cognição humana envolve linguagem e pensamento abstrato e, portanto, símbolos e representações mentais, mas o pensamento abstrato é apenas uma parcela da cognição humana, e geralmente não é a base para as nossas decisões e as nossas ações. As decisões humanas nunca são completamente racionais, estando sempre coloridas por emoções, e o pensamento humano está sempre encaixado nas sensações e nos processos corporais que contribuem para o pleno espectro da cognição" (Capra, 1996, p. 216).

Em que pesem as graves conseqüências das distorções causadas pelo pensamento tecnicista para a efetividade da gestão de sistemas estratégicos de informação, o fetiche da TI traz prejuízos ainda maiores na medida em que cria a ilusão de uma mudança qualitativa na sociedade, que confunde e enfraquece uma ação verdadeiramente transformadora por parte da sociedade.

\section{A TI PODE, SOZINHA, MUDAR O MUNDO?}

Naisbitt et al. (1999, p. 26) relatam que os "tecnólogos" mais ferrenhos assumem que o acesso universal à Internet equivale à criação da paz mundial, garantindo o destino da humanidade e a saúde do planeta e da economia global. Existe a crença de que a tecnologia pode impelir as nações para um sistema internacional cooperativo. Em suas críticas aos ferrenhos defensores da TI, os referidos autores dizem que eles promovem a net como um lar para todos e imaginam um futuro no qual os estudantes serão esforçados, os funcionários, judiciosos e os consumidores, bem informados e onde os cidadãos exercerão plenamente sua liberdade de expressão. Para os "tecnófilos", as ciências genéticas não só podem alterar para melhor a evolução humana, como têm ainda o poder de salvar o planeta da fome e das desigualdades sociais.

Para muitos pesquisadores, a reestruturação contínua da economia é fundamentalmente acarretada pelos avanços da TI (Tapscott e Caston, 1993), principalmente quando se entende que a onda de inovação revolucionária resultante das tecnologias emergentes, como a engenharia genética, origina-se na evolução da capacidade de processamento, armazenagem e comunicação da informação e com ela se confunde (Day e Schoemaker, 2000). Alguns estudiosos já contestaram esse determinismo tecnológico que atribui à TI um caráter implicitamente revolucionário, embora ainda manifestem a esperança de que ela possa dar um significado mais humano às práticas de trabalho nas organizações, mesmo que dentro dos limites da razão puramente instrumental (Durand, 1994).

A visão tecnicista, apoiada na razão instrumental, tem conduzido a uma competição permanente, produtora de ansiedades e de patologias psíquicas (Serva, 1997), sintomas esses que podem ser perfeitamente associados à visão mitificadora da TI na sociedade atual. O quadro de patologias psíquicas é tão grave, que já é comum observarmos megaexecutivos autoproclamarem-se, com indisfarçável orgulho, "paranóicos", de sorte que a tecnologia pode significar não apenas aportes de melhorias, mas pode gerar uma tendência gradual à escravização tecnológica (Mattos, 1996). Por exemplo, nota-se, nas sociedades contemporâneas, a existência de uma psicopatologia, a tecnose, originada na dependência exagerada e no uso compulsivo da TI e na apologia da velocidade. Os dependentes dessa doença mental buscam preencher, por meio da informação e da hipercomunicação em um ritmo cada vez mais veloz, efêmero, descartável e frustrante -, o vazio deixado pela falta de uma visão que dê significado à sua existência diária.

Dentro da epistemologia moderna, as tecnologias da informação tornaram-se autônomas e totalitárias, subordinando a cultura à tecnologia, empobrecendo valores humanos básicos e eliminando visões alternativas de mundo, mantendo a visão moderna de progresso como algo dissociado do bem-estar humano (Capra, 1996). O desenvolvimento científico, catapultado pela revolução 
da informática, resultou na instabilidade do sistema técnico, que se evidencia na incapacidade do poder público de medir a ameaça que a aceleração das tecnociências significa (Ramonet, 2000).

Apesar da valorização dos benefícios da TI e da ideologia produtivista que a incorpora, com relação à humanidade, o que o observador percebe é um cenário de destruição ecológica acelerada e irreversível; o empobrecimento crescente de vastas regiões do globo; o afastamento do estado de suas obrigações básicas como segurança, educação e habitação e o abandono dos indivíduos, tornados obsoletos pela revolução tecnológica, à sua própria sorte. Insensíveis a esse quadro de degradação física e moral do mundo, a mídia e a universidade, a serviço da razão instrumental, do cinismo corporativo e da indústria de computadores, veiculam as maravilhas do mundo conectado: um cenário paradoxal muito próximo do futuro sombrio aventado por Ridley Scott no cult movie "Blade Runner" e completamente diferente do nirvana proposto pelos tecnófilos.

$\mathrm{Na}$ busca de um caminho alternativo, confrontamos, neste artigo, o mito ou a perspectiva da TI como promotora, em si, de uma revolução social. Na verdade, o bemestar social ocasionado pela tecnologia foi excludente e não se espalhou para o conjunto da humanidade, visto ser a tecnologia um instrumento, objeto de uma ideologia e de uma forma de razão que se dissociou de um pensar substantivo que a deveria comandar. Dentro da visão de mundo dominante, a tecnologia continua a ser aplicada principalmente para melhorar as condições econômicas das camadas sociais mais beneficiadas pelo sistema social vigente. Para mudar tal quadro, é necessária uma nova visão do mundo, na qual o tecnicismo e o pensar instrumental sejam subordinados à razão substantiva, que é essencialmente moral, holística, preocupada com o entendimento da natureza e do ser humano e, por isso, crítica.

De fato, são as formas de conhecer o mundo e a qualidade do processo de mudança daí derivado que vão permitir estratégias, organizações e sociedades que superem as injustiças sociais e a degradação ecológica, e não a existência de uma maior capacidade de coletar, armazenar, interpretar e compartilhar informação. É a tecnologia a serviço de uma razão substantiva que permitirá o aproveitamento mais abrangente do know-how acumulado pela humanidade. Dito isso, a questão mais importante, na atualidade, passa a ser o conhecimento, e a crise geral é, na verdade, uma crise da forma pela qual conhecemos o mundo (Capra, 1996).

A essa altura, deve ficar claro que as mudanças possibilitadas pela TI limitam-se a modificações superficiais de estruturas, comportamentos e processos, mas não alcançam os modelos mentais ou os pressupostos de conhecimento que caracterizam o paradigma funcionalista (Leitão e Rossi, 2000). Desse modo, para superar o tecnicismo instrumental das promessas da grande maioria dos especialistas de TI, é preciso primeiro questionar os pressupostos epistemológicos subjacentes, se quisermos humanizar o sistema produtivo vigente.

\section{EPISTEMOLOGIAS ALTERNATIVAS: A SUPERAÇÃO DO PENSAR TECNICISTA}

Ao buscar transpor os limites do modernismo, as preocupações de maior profundidade na pesquisa organizacional têm girado em torno de questões de ontologia, epistemologia e metodologia (Steffy e Grimes, 1996). Não se pode subscrever cegamente a narrativa de progresso do tecnicismo com seu pressuposto de progressão linear e unitária, que serve tão- somente para suprimir a possibilidade de múltiplas alternativas (Hassard, 1996). A preocupação central com o potencial das perspectivas teóricas emergentes deve ser a de oferecer novas possibilidades à nossa cultura, já que a ciência "normal" parece ter esgotado sua capacidade de explicação dos fenômenos sociais.

\section{Reduzir A COMUNICAÇÃO}

\section{HUMANA A UMA SIMPLES}

\section{TRANSMISSÃO DE INFORMAÇÃO}

\section{OBJETIVA É SUPRIMIR TODA}

\section{A QUESTÃO DO SENTIDO E DAS SIGNIFICAÇÕES.}

A incerteza de nossas teorias decorre da falha da ciência em vender sua narrativa como uma forma de conhecimento superior, no sentido substantivo, a todas as outras formas de conhecimento (Burrel, 1999). Tem-se a impressão de que a ciência saiu de seu leito, tornando-se mister trazer para seu lado outras epistemologias, como a filosofia, a arte e a religião. Assim, novas narrativas e novas epistemologias, como também uma volta às velhas tradições culturais da humanidade, parecem agora mais necessárias do que nunca (Weil, 1993).

Sem nenhuma pretensão de reduzir a discussão epistemológica às correntes e temas discutidos a seguir, temos por objetivo tão-somente evidenciar como outras opções de conhecer - tais como a visão sistêmica, a teoria crítica e o pós-modernismo - permitem ao pesquisador desenvolver uma postura crítica ao tecnicismo do discurso da TI e, ao mesmo tempo, romper o paradigma modernista nas ciências sociais, de modo a colocar o bemestar humano e a saúde de nosso planeta como temas centrais da pesquisa acadêmica a serviço de uma prática social transformadora. 


\section{Visão sistêmica dos fenômenos sociais}

Segundo Chia (1995), o pensamento modernista contém uma crença fundamental, firmemente embutida na epistemologia e apoiada na isolamento de diferentes aspectos da experiência humana. Coisas, eventos e entidades sociais podem ser isoláveis e, assim, identificáveis como sistemas ou estados nas dimensões espaço-temporais. Nessa perspectiva, o conhecimento procura capturar e representar os aspectos primários do mundo material e social, explicando-os dentro de relações causais. Ainda segundo o autor, esse sistema idealmente isolado está intimamente ligado a uma ontologia do "ser", em que o conhecimento é discreto e cumulativo e os campos de saber são isolados para que não "infectem" uns aos outros. Para Capra (1996, p. 41), a perspectiva reducionista do paradigma cartesiano-newtoniano apóiase na "crença segundo a qual em todo o sistema complexo o comportamento do todo pode ser entendido inteiramente a partir das propriedades de suas partes".

Sob a influência desse paradigma, o conhecimento fragmentou-se em inúmeras disciplinas isoladas, que podem ser divididas em dois grandes grupos: aquelas que buscam o conhecimento puro e as que pertencem à área da tecnologia e envolvem métodos e técnicas de ação (Weil, 1993). No paradigma sistêmico, ao contrário, observa-se que todas as formas de conhecimento são limitadas e aproximadas e dependem da epistemologia subjacente a elas (Capra, 1996). Portanto, quanto mais se estudam os principais problemas da atualidade, sejam eles naturais, sejam sociais, mais se é levado a perceber que eles não podem ser entendidos como uma coleção de objetos isolados, pois são problemas sistêmicos, já que estão interligados e interdependentes em um todo (Capra, 1996).

Dentro de uma visão sistêmica, as propriedades essenciais de um sistema vivo são propriedades do todo, e as propriedades das partes só podem ser compreendidas dentro do contexto do todo. Mais do que isso, as propriedades sistêmicas são destruídas se um sistema é dissecado em elementos isolados (Capra, 1996). Nessa nova ciência da interdependência sistêmica, prevalecem as noções de autodeterminação, auto-organização e auto-renovação (Weil, 1993), mas com uma mudança do foco em objetos para o foco em relações em redes e padrões.

Podem-se associar os métodos de análises reducionistas e instrumentais dos processos afetados pela TI nas organizações ao paradigma cartesiano-newtoniano, que isola, ao invés de relacionar. Por ironia, o mesmo método volta-se contra os profissionais de TI, quando esses se vêem privados da participação em etapas críticas da formulação de estratégia, como nas fusões e aquisições. Ao contrário, os fenômenos organizacionais, como a mudança, precisam ser compreendidos e explicados por palavras e esquemas visuais, por meio de formas de expressão lingüistica e por um pensar sistêmico que inter-relacione, ao invés de reduzir (Leitão e Rossi, 2000).

\section{Teoria crítica na sociologia das organizações}

A teoria crítica tem seus estudos organizacionais embasados, prioritariamente, nos conceitos da Escola de Frankfurt - da qual participavam Adorno, Horheimer, Marcuse e Fromm - e na teoria crítica contemporânea de Jürgen Habermas (Steffy e Grimes, 1996). De forma sucinta, pode-se dizer que a teoria crítica assume que teorias, sistemas de conhecimento e fatos são subsistemas fechados que refletem visões de mundo relativas. Nesse sentido, teorias são meros insights e representam estratégias práticas para problemas organizacionais. Os teóricos críticos estão focados na distorção e no estreitamento do discurso histórico provocados pela reificação, pela unificação de interesses de segmentos sociais e pela absoluta dominação da racionalidade instrumental (Alvesson e Deetz, 1999).

Do ponto de vista metodológico, a teoria crítica tem dois objetivos principais (Steffy e Grimes, 1996). Primeiro, uma crítica ao culto do "cientificismo" nas ciências sociais, que, no ambiente organizacional, se traduz na dominação quase absoluta da razão técnica. Para combater essa perspectiva, a teoria crítica preconiza um método analítico que questione os pressupostos ontológicos e epistemológicos dominantes na pesquisa. O segundo objetivo é desenvolver uma ciência organizacional capaz de mudar os próprios processos, o que exigirá uma investigação da inter-relação dinâmica entre pesquisa, teoria, prática e membros das organizações e a aplicação da práxis transformadora. Por conseguinte, a meta central dos teóricos críticos nos estudos organizacionais tem sido criar sociedades e lugares de trabalho livres da dominação, em que todos os membros tenham igual oportunidade de contribuir para a produção de ecossistemas que venham ao encontro das necessidades humanas e que conduzam ao desenvolvimento de todos (Alvesson e Deetz, 1999).

De acordo com Steffy e Grimes (1996), a teoria crítica assume que os constructos de primeiro nível são formados por uma epistemologia normativa, na qual os atores organizacionais e os eventos estão infusos em valores, crenças e atitudes preconcebidas, construídos por meio do processo de seleção e socialização. A teoria crítica assume também que a visão de mundo do pesquisador constitui-se em um constructo de terceiro nível, pois os teóricos e pesquisadores não podem ser considerados donos de uma razão objetiva, livre dos valores obtidos por meio de treinamentos e influências do grupo e da organização à qual estão filiados.

Habermas distingue, em Communication and the evolution of society (1979), dois modos de ação: a) ação purposive-rational, na qual a ordem social é construída a partir de um raciocínio técnico, e o ator social é visto como um instrumento para alcançarem-se os objetivos dessa ordem; b) ação comunicativa, na qual a ordem social é normativamente definida por meio do relacionamento social de atores subjetivos (Steffy e Grimes, 1996). No primeiro caso, o conhecimento organizacional é validado 
por meio de critérios objetivos e mensuráveis. No segundo, a validação ocorre por meio do consenso.

Dentro de uma perspectiva sociolingüística, grupos constroem e adotam uma linguagem própria, que consiste em símbolos compartilhados, por meio dos quais o significado é objetivado e comunicado. Quando o consenso obtido da comunicação é substituído pela racionalidade técnica, a validação do conhecimento é retirada do grupo social e passa a prevalecer uma linguagem técnica unidirecional, especializada e precisa. Consequientemente, as questões práticas da vida organizacional são transformadas em questões técnicas, e a tecnologia, então, passa a ser um meio de controle.

Um estudo amparado na teoria crítica possibilita um questionamento do caráter mítico da TI. Por um lado, ficam claras as limitações da razão tecnicista das atuais tentativas de gestão de mudança organizacional pela implantação de modelos centrados na TI. Por outro, por sua preocupação com a práxis transformadora, possibilita colocar em questão como a TI pode contribuir, na condição de habilitadora, para desenvolver uma ciência organizacional capaz de humanizar os processos organizacionais e criar sociedades e ambientes de trabalho menos opressores.

\section{Visão pós-moderna}

Para Weil (1993), a dualidade sujeito/objeto da epistemologia moderna, que suporta o uso fragmentado e indiscriminado da tecnologia, está prejudicando a vida no planeta. Portanto, novas perspectivas epistemológicas ganham terreno em função da crise do discurso modernista, com sua racionalidade instrumental, com seu saber técnico-científico inquestionável, com sua gestão centrada no controle e com a submissão crescente e irresponsável da natureza e das pessoas à visão economicista (Alvesson e Deetz, 1999).

O pós-modernismo é um conjunto de abordagens filosóficas que também se aplica ao estudo das organizações e que emerge a partir da obra de Derrida e Foucault (Alvesson e Deetz, 1999). Uma das razões principais para o crescimento de uma perspectiva teórica pós-modernista na pesquisa organizacional é a desilusão de alguns estudiosos em relação ao trabalho supersimplificado, desapontador e substantivamente irrelevante que a ciência moderna oferece, com seus modelos mecanicistas de comportamento humano e com o menosprezo do entendimento subjetivo em favor de técnicas quantitativas (Kilduff e Mehra, 1997).

No pós-modernismo, há uma rejeição às proposições estabelecidas e ao consenso presumido, com uma conseqüente aceitação do pluralismo, da diferença, da dissonância e da heterogeneidade, além de uma admissão irônica da efemeridade das coisas, inclusive do próprio saber (Kilduff e Mehra, 1997). A realidade é um fluxo em transformação, e o conhecimento não é um processo individual, mas envolve o indivíduo, a coletividade e os objetos de pesquisa. Nesse contexto, o conhecimento do mundo só é possível por meio dos discursos particulares criados pela linguagem e pela visão sintética dos fenômenos (Hassard, 1996). Os seres humanos não podem ter acesso a seu próprio campo cognoscitivo a partir "de fora" desse campo (Maturana e Varela, 1995).

\section{A VISÃO REIFICANTE DA TI}

\section{NA TEORIA DE GESTÃO, QUE}

\section{CONSIDERA ESSA TECNOLOGIA}

\section{COMO REDENTORA DA}

\author{
HUMANIDADE, NÃO TEM \\ NADA DE NOVO; SEGUE A \\ TRADIÇÃO TECNICISTA DA \\ VISÃO MODERNA DE MUNDO.
}

A perspectiva pós-modernista procura romper as estruturas normativas e explodir o mito das relações estruturais robustas, propondo, no lugar, a fragilidade da vida organizacional. Os constructos utilizados para entender as organizações são imperativos morais, que servem para pressupor certas características enquanto excluem outras (Hassard, 1996). O foco legítimo da organização pósmoderna passa a ser as micropráticas e as micrológicas do organizar, por meio da orquestração local das ações, interações e padrões interligados de relações (Chia, 1995).

$\mathrm{Na}$ epistemologia pós-moderna, são consideradas ingênuas e equivocadas as tentativas de descobrir a ordem genuína das coisas por métodos empíricos, propondo-se uma reposição do fatual pelo representacional (Hassard, 1996). O foco do pós-moderno não é mais o "ser", mas o "tornar-se" e, portanto, privilegia-se a ação, o movimento, o processo e a emergência (Chia, 1995). O pós-modernismo aceita métodos como a etnografia, as biografias, as histórias vividas e contadas, a desconstrução textual, a interpretação semiótica e a intermediação da linguagem (Kilduff e Mehra, 1997). O que o método pós-moderno procura derrubar é a tendência de abstrair idéias seletivamente, concretizá-las como aspectos essenciais da realidade e, então, tomá-las como unidades apropriadas de análise, ignorando o processo havido de descontextualização (Chia, 1995). Na perspectiva pós-moderna, a linguagem não é uma escrava da observação e da razão objetiva (Hassard, 1996), devendo-se, pois, adotar uma postura crítica em relação aos pressupostos intelectuais a ela subjacentes.

A utilização de uma abordagem pós-moderna permite analisar, criticamente, alguns pressupostos subjacentes à literatura de TI. Por exemplo, o questionamento da pre- 
ocupação científica com o objeto mitificado, nesse caso a TI, abre caminho para desmascarar a hipótese de que mais tecnologia - vista como variável independente -, irá conduzir inexoravelmente ao progresso social - visto como a variável dependente -, o que, por sua vez, possibilita ao pesquisador situar a TI dentro dos limites de um habilitador de estratégias empresariais. A busca de dados por meio representacional, por outro lado, auxilia, a partir das histórias vividas nas implantações de sistemas de informação, na percepção do impacto da hipertrofia da razão instrumental e da ideologia produtivista no comportamento dos atores organizacionais.

\section{POR UM DESENVOLVIMENTO TECNOLÓGICO SUBORDINADO A UMA RAZÃO SUBSTANTIVA}

O grande e reconhecido desenvolvimento técnico, gerado a partir da visão de ciência cartesiana-newtoniana e, de certa forma, alavancado pela fragmentação do saber, trouxe o sacrifício de uma visão holística e da razão substantiva, criando problemas éticos e sociais que afetam a humanidade (Leitão e Rossi, 2000). Na medida em que a ciência atual parece não ter respostas para os dilemas mais profundos da sociedade contemporânea, pode-se afirmar que "a epistemologia de Newton e Descartes trouxe em seu bojo a necessidade de sua própria superação" (Leitão e Rossi, 2000, p. 20). À parte o embate epistemológico em si, que deverá ser necessariamente travado, a urgência de uma mudança paradigmática impõe-se por uma necessidade pragmática - argumento tão ao gosto da visão tecnocrática - de salvar a vida em nosso planeta, ameaçada pelas conseqüências nefastas das aplicações tecnológicas dentro dos limites da razão instrumental (Weil, 1993).

A visão reificante da TI na teoria de gestão, que coloca essa tecnologia como redentora da humanidade, não tem, a rigor, nada de novo. Segue a tradição tecnicista da visão moderna de mundo. Conseqüentemente, não surpreende que, na imensa maioria dos casos, as mudanças acarretadas pela aceleração na utilização da TI quase sempre sirvam para ampliar as formas de dominação e de submissão do ser humano à lógica produtivista e ao consumismo.

Ao analisar-se a qualidade das mudanças desencadeadas pela TI no ambiente organizacional nas duas últimas décadas, que, certamente, serão aceleradas com o crescimento da Internet, percebe-se que, aqui também, prevalecem o reducionismo científico, a ideologia produtivista, o paradigma funcionalista, a razão instrumental e a lógica técnica. Nesse quadro, "a mudança se dará nos limites da técnica instrumentalizadora e dos valores e crenças do produtivismo, que são percebidos como possibilidade única para as organizações sociais no paradigma vigente" (Leitão e Rossi, 2000, p. 12). O pensamento sistêmico, ao contrário, "envolve uma mudança da ciência objetiva para a ciência 'epistêmica', para um arcabouço no qual a epistemologia - o método de questionamento - torna-se parte integral das teorias científicas" (Capra, 1996, p. 49).

No debate sobre o papel da TI nas organizações e na sociedade, é preciso reconhecer que as tarefas genuinamente humanas, tais como sabedoria, compaixão, respeito, compreensão e amor, a partir das quais poderá confrontar-se a razão instrumental que fundamenta ideologicamente a submissão do homem e da natureza aos imperativos econômicos, jamais poderão ser realizadas pelo computador (Capra, 1996). Essas são algumas tarefas indelegáveis dos homens e de sua práxis política. Elas nascem de um estado de consciência, de uma percepção da necessidade de harmonia com a natureza essencial das coisas, de um sentido da unidade presente na humanidade, unidade essa que não é apenas biológica ou apenas cultural, mas que se enraíza em uma realidade mais profunda que inclui toda a vida em nosso planeta (Lemkow, 1990).

Do ponto de vista sistêmico, holístico, de ecologia profunda (Capra, 1996), os profissionais envolvidos com a gestão da TI nas organizações, o que não se reduz aos especialistas em TI, devem fazer mais do que ampliar a eficácia dos processos subjacentes às mudanças adaptativas desencadeadas pela tecnologia. Devem buscar uma melhor compreensão da ontologia e da epistemologia da informação e enxergar os fenômenos associados à TI como parte de um problema mais amplo, envolvendo múltiplos aspectos inter-relacionados. Dentro da perspectiva da razão substantiva, que pode superar os pressupostos sociotécnicos do paradigma funcionalista, permanece praticamente sem resposta a necessidade de inserir a gestão da TI em um debate ético-valorativo (Serva, 1997) das mudanças mais amplas da organização e da sociedade.

Para as mentes mais pragmáticas, pode ser frustrante não se propor aqui um método que ensine a subordinar o que é instrumental ao que é substantivo. Uma mudança paradigmática dessa envergadura, que envolve a própria maneira como conhecemos o mundo, levará anos e está longe de estar garantida (Burrel, 1999). De fato, trata-se de uma mudança da ideologia dominante, cujo objetivo final será desmitificar o conjunto de crenças e valores que visam à manutenção de uma ordem social dominada pelo economicismo e pela ilusão do progresso técnico inexorável. Seu sucesso, portanto, dependerá de nossa capacidade de superar posturas puramente esotéricas e niilistas pela ação política firme e determinada de intelectuais, cientistas, políticos, religiosos, trabalhadores e organizações sociais comprometidos com a busca de um futuro mais equilibrado e duradouro para o conjunto da humanidade.

Como corolário final das breves observações acima, lança-se mão das palavras de Capra (1996, p. 26) ao explicar o paradigma da ecologia profunda, as quais deveriam servir para levar os defensores do caráter emancipador da TI a um posicionamento mais humilde, colocando seu objeto de estudo a serviço de objetivos sociais mais am- 
plos e integrados: "Precisamos estar preparados para questionar cada aspecto isolado do velho paradigma. Eventualmente, não precisaremos nos desfazer de tudo, mas antes de sabermos isso, devemos estar dispostos a questionar tudo. Portanto, a ecologia profunda faz perguntas profundas a respeito do próprio fundamento da nossa visão de mundo e do nosso modo de vida modernos, científicos, industriais, orientados para o crescimento e materialistas. Ela questiona todo esse paradigma com base em uma perspectiva ecológica: a partir da perspectiva de nossos relacionamentos uns com os outros, com as gerações futuras e com a teia da vida da qual somos parte." $\bigcirc$

\section{REFERÊNCIAS BIBLIOGRÁFICAS}

ALVESSON, M., DEETZ, S. Teoria crítica e abordagem pósmoderna. In: CLEEG, S. R., HARDY, W. R., NORD, C. Handbook de estudos organizacionais. São Paulo : Atlas, 1999.

ASTLEY, Graham, W., VAN DE VEN, Andrew. H. Centra perspectives and debates in organizacional theory. Administrative Science Quarterly, v. 28, p. 245-273, 1983.

BAUM, J. A. C. Ecologia organizacional. In: CLEEG, S R., HARDY, W. R., NORD, C. Handbook de estudos organizacionais. São Paulo : Atlas, 1999.

BENJAMIN, R. I., LEVINSON, E. A framework for managing IT-enabled change. Sloan Management Review, v. 34, n. 4, p. 23-33, 1993.

BENSAOU, M., EARL, M. The right mind-set for managing information technology. Harvard Business Review, v. 76 n. 5 , p. $119-130,1998$

BIRKNER, R. M., BIRKNER, L. R. The common thread of biologist and learning organization structure: nature's lessons in growth and change prove instructive. Occupational Harzards, v. 61, n. 8, p. 8-32, Aug. 1999.

BURREL, G. Ciência normal, paradigmas, metáforas, discursos e genealogia da análise. In: CLEEG, S. R., HARDY, W. R., NORD, C. Handbook de Estudos Organizacionais. São Paulo : Atlas, 1999.

BURREL, G., MORGAN, G. Sociological paradigms and organizational analysis: elements of sociology of corporate life. London : Heineman, 1982.

CAPRA, F. A teia da vida. São Paulo : Cultrix, 1996.

CHANLAT, J.-F. Por uma antropologia da condição humana nas organizações. In: . O individuo nas organizações. São Paulo : Atlas, 1992. V. 1.

CHANLAT, J.-F. Ciências Sociais e management. São Paulo : Atlas, 2000.

CHIA, R. From modern to postmodern organizational analysis. Organizational Studies, v. 16, n. 4, p. 579-605, 1995.

DAVIS, S., MEYER, C. Blur: the speed of change in the connected economy. New York: Warner Books, 1998.

DAY, G. S., SCHOEMAKER, P. J. H. Wharton on managing emerging technologies. New York : John Wiley \& Sons, 2000.

DE ALMEIDA, F. C. Novo modelo organizacional baseado no cérebro humano. Revista de Administração, v. 30, n. 1, p. 46-56, 1995.

DURAND, J. P. A tecnologia da informação e o legado do taylorismo na França. RAE - Revista de Administração de Empresas, v. 34, n. 1, p. 82-99, 1994.

EVANS, P., WURSTER, T. Blow to bits: how the new economics of information transform strategy. Boston Harvard Business School Press, 2000.
FORD, J. D., FORD, L. W. The role of conversations in producing intentional change in organizations. Academy of Management Review, v. 20, n. 3, p. 541-570, 1995.

GATES, B. A empresa na velocidade do pensamento. São Paulo : Companhia das Letras, 1999.

GOLEMAN, D. Inteligência emocional. 3. ed. Rio de Janeiro : Objetiva, 1996.

GONÇALVES, G. J. Sistemas de informações automatizados: uma análise crítica sobre a sua eficácia. Dissertação (Mestrado) - Instituto de Administração e Gerência, Pontifícia Universidade Católica do Rio de Janeiro, 1996.

HABERMAS, J. R. Communication and the evolution of society. Boston : Beacon Press, 1979.

HASSARD, J. Exploring the terrain of modernism and postmodernism in organization theory. In: BOJE, D. M. GEPHART JR., R. P. THATCHENKERY, T. Post modern management and organization theory. London: Sage, 1996.

JAHN, R. G., DUNNE, B. J. Science of the subjective. 1997. Disponivel em: <http://www.jse.com/jahn/1.html>.

KEEN, P. G. W. Shaping the future: business design through information technology. Boston: Harvard Business School Press, 1991.

KILDUFF, M., MEHRA, A. Postmodernism and organizational research. Academy of Management Review, v. 22, n. 2, p. $453-482,1997$.

KOVACEVIC, A., MAJLUF, N. Six stages of IT strategic management. Sloan Management Review, v. 34, n. 4, p. 77-88, 1993.

LEFEBVRE, H. Lógica formal/lógica dialética. Rio de Janeiro : Civilização Brasileira, 1979.

LEITÃO, S. P., ROSSI, L. P. Natureza da mudança nas organizações: uma introdução crítica. Revista Archè Interdisciplinar, v. 10, n. 28, p.13-38, 2000.

LEMKOW, A. F. Como caracterizar a nova era? In : Aquariana, 1990. O princípio da totalidade. São Paulo

LEVITT, B., MARCH, J. G. Organizational learning. In: COHEN, M. D., STROULL, L. S. Organizational learning. London: Sage, 1996.

LOCKAMY III, A., SMITH, W. I. A. Strategic alignment approach for effective business process reengineering: linking strategy, processes and customers for competitive advantage. International Journal of Production Economics, v. 50, p. 141-153, 1997.

MARKUS, M. L., BENJAMIN, R.I. The magic bullet theory in IT-enabled transformation. Sloan Management Review, v. 38, n. 2, p. 55- 68, 1997.

MATTOS, F. G. Cultura e valores no processo de internacionalização das economias: o desafio humano. In: FÓRUM INTERNACIONAL DE ADMINISTRAÇÃO, 4., 1996 Miami. Revista Brasileira deAdministração, ano 5, n.17, p.7176, 1996. Número especial com os anais do IV Fórum Internacional de Administração.
MATURANA, H., VARELA, F. A árvore do conhecimento. Campinas: Psy, 1995

NAISBITT, J., NAISBITT, N., PHILIPS, D. High tech - high touch: a tecnologia e a nossa busca por significado. São Paulo : Cultrix, 1999.

NEGROPONTE, N. A vida digital. São Paulo: Companhia das Letras, 1995.

QUINCEY, C. Engaging presence: exploring consciousness from the second-person perspective. Noetic Sciences Review, v. 45, p. 24-27, 1998.

RAMIREZ, R. Value co-production: intellectual origins and implications for practice and research. Strategic Management Journal, v. 20, p. 49-65, 1999.

RAMONET, I. A necessidade da utopia. Jornal do Brasil, 19 nov. 2000. Encarte Le Monde Diplomatique.

REMENYI, D., WHITE, T., SHERWOOD-SMITH, M. Language and a post-modern management approach to information systems. International Journal of Information Management, v. 19, p. 17-32, 1999.

SERVA, M. A racionalidade substantiva demonstrada na prática administrativa. RAE - Revista de Administração de Empresas, v. 37, n. 2, p. 18-30, 1997.

STEFFY, B. D., GRIMES, A. J. A critical theory of organization science. Academy of Management Review, v. 11, n. 2, p. $322-336,1986$

STEVENSON, W. B., GREENBERG, D. N. The formal analysis of narratives of organizational change. Journal of Management, v. 24, n. 6, p. 741, Nov./Dec. 1998.

TAPSCOTT, D., CASTON, A. Paradigm shift: the new promise of information technology. New York : McGrawHill, 1993

VAN DE VEN, A. H., POLLE, M. S. Explaining development and change in organizations. Academy of Management Review, v. 20, n. 3, p. 510-540, 1995.

VENKATRAMAN, N. IT-enabled business transformation: from automation to business scope redefinition. Sloan Management Review, v. 35, n. 2, p.73-87, 1994.

VILLARDI, B. Q., LEITÃO, S. P. Organização de aprendizagem e mudança organizacional. Revista de Administração Pública, v. 34, n. 3, p.53-70, 2000.

WALSH, J. P. Managerial and organizational cognition: notes from a trip down memory lane. Organization Science, v. 6, n. 3, p. 280-321, 1995.

WEIL, P. Axiomática transdisciplinar para um novo paradigma holístico. In: WEIL, P., D'AMBROSIO, U., CREMA, R. Rumo à nova transdisciplinaridade. São Paulo : Summus, 1993.

ZUBOFF, S. Automatizar/informatizar: as duas faces da tecnologia inteligente. RAE - Revista de Administração de Empresas, v. 34, n. 6, p. 80-91, 1994. 